\title{
Pyrolysis Characteristic Study on Oily Sludge from North China Oilfield
}

\author{
Zheng Chang, a , Zhaoquan Chen ${ }^{1}$ and Yinqi Feng ${ }^{1, b}$ \\ ${ }^{1}$ Department of Mechanical Engineering, \\ Beijing Institute of Petrochemical technology \\ Beijing 102617, P.R. China \\ achangzheng@bipt.edu.cn, ${ }^{\text {b }}$ fengyinqi@bipt.edu.cn
}

Keywords: oil sludge; pyrolysis; calorific value.

Abstract. Using a microcomputer differential thermal balance, oil pyrolysis experiments on oily sludge samples were researched at different heating rates. Pyrolysis reactions with heating rates, temperature and time were analyzed. Their combustion calorific values were obtained through calorimetric experiments as well.

\section{Introduction}

With the shortage of natural resources and the increase of solid waste discharges in the world, many countries take solid wastes as "resources" for comprehensive utilization [1]. Oily sludge, as one of the solid wastes, is a very stable suspension emulsion fluid with very complex compositions. It contains a large amount of organic matter and harmful substances. These harmful substances will not only seriously damage the ecological environment, but also seriously affect the normal operation of oil factories and refinery [2,3]. However, its organic matters with high calorific value can be pyrolyzed and used by a pyrolysis method. And their oil and gas can also be recovered $[4,5]$. In this paper, pyrolysis characteristics and calorific value determination were studied experimentally using oily sludge samples from a sewage treatment field on North China oilfield.

\section{Experimental methods}

Temperatures are set in the range from room temperature to $600{ }^{\circ} \mathrm{C}$, and heating rate is set $10{ }^{\circ} \mathrm{C} / \mathrm{min}$, about $10 \mathrm{mg}$ oil sludge is put on the computer differential thermal balance of a TG/DTA6300 thermo-gravimetric analyzer. During experiments, experimental data were recorded and experimental phenomena were observed.

Calorific values of oily sludge samples are measured using a XRY-1A oxygen bomb calorimeter. $2.98 \mathrm{~kg}$ water was taken through the platform, and oxygen was charged in oxygen bomb until its pressure to be $2 \mathrm{MPa}$. Small amount of oxygen filled will result in sample's incomplete combustion and experimental data will be deviated.

\section{Pyrolysis experimental data}

Oil sludge pyrolysis process can be divided into two stages. The temperature $0 \sim 200^{\circ} \mathrm{C}$ is in the first stage which is an evaporation stage where oil sludge loses water. The temperature of 200 600 degrees Celsius is in the second stage which is pyrolysis stage of the oil sludge. The thermos-gravimetric curves of three samples are shown in Fig.1. The amount of their residues is different after pyrolysis reaction. Sample 1 contains less oil, sample 2 is almost all oil, and sample 3 contains the least oil. That is the oil content of sample 2 is bigger than that of sample 1, and the oil content of sample1 is bigger than that of sample 3 . 


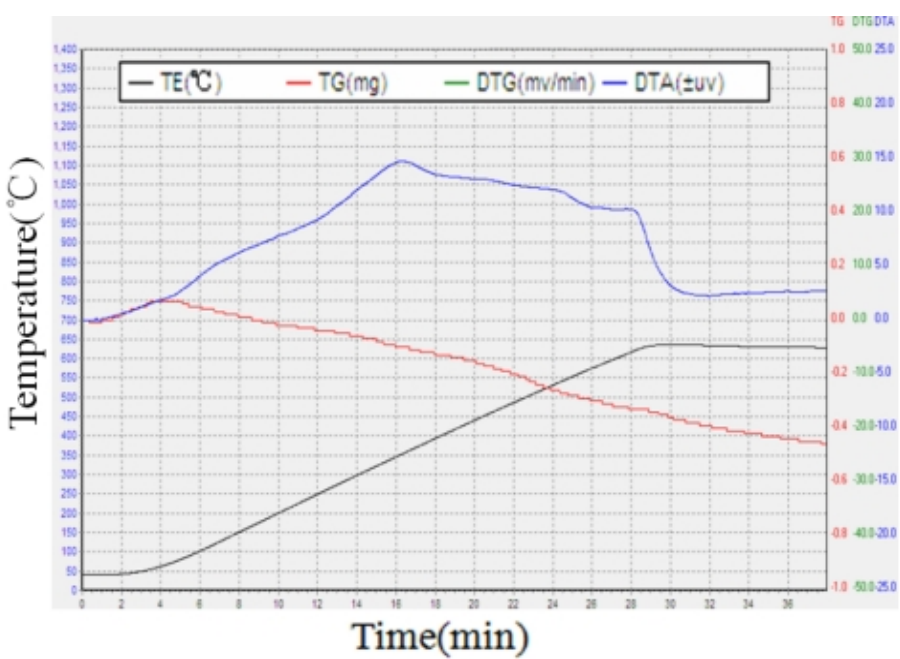

a) Sample 1

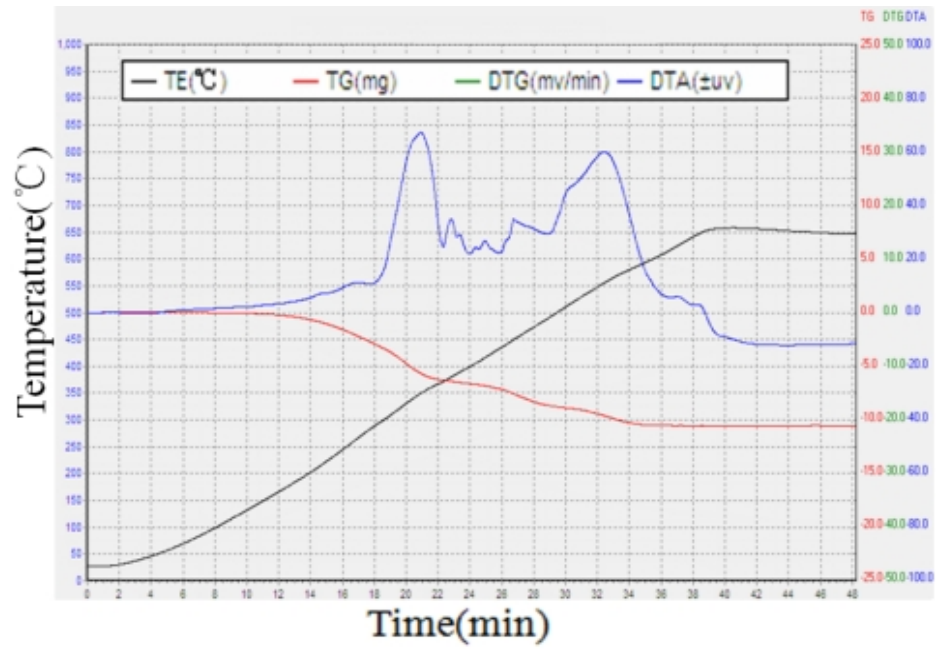

b) Sample 2

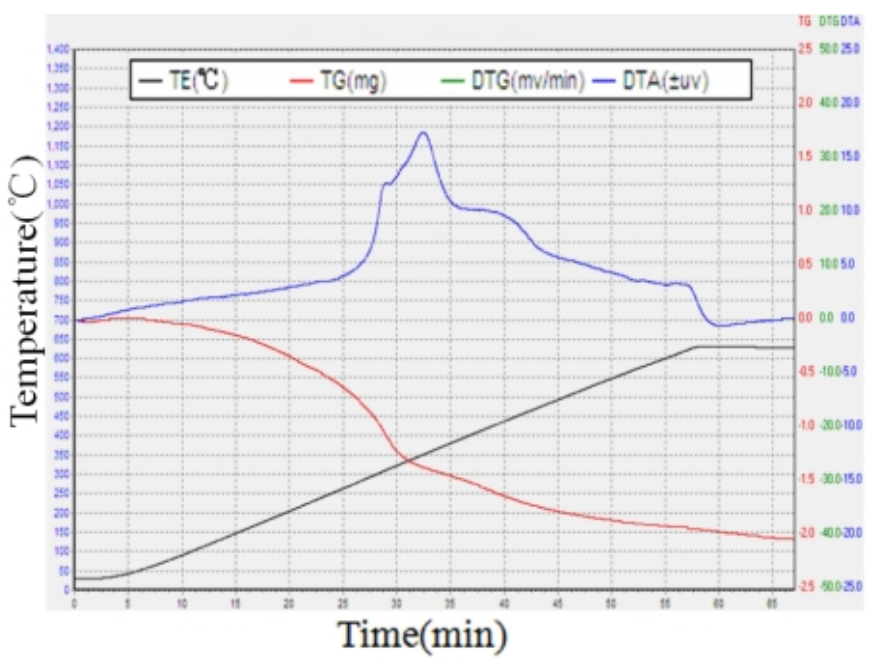

c) Sample 3

Fig.1 Thermo-gravimetric curves of 3 samples 
From the data of these three samples and their thermos-gravimetric curves given in Fig. 1, a main factor affecting oil sludge pyrolysis processes is temperature. When temperature at $200^{\circ} \mathrm{C}-400^{\circ} \mathrm{C}$ thermal decomposition efficiency is most highest. However, in these experiments, different heating rate on thermal weight curves is not obvious. That is, heating rates has little effect on pyrolysis processes.

\section{Major Calorific value determination}

Calorific values of sample 1 and sample 2 was measured. Their experimental data are shown in Table 1 .

Table 1 Experimental data for calorific value measurement

\begin{tabular}{ccccc}
\hline Name & $\begin{array}{c}\text { Sample } \\
\text { Quality }(\mathrm{kg})\end{array}$ & $\begin{array}{c}\text { Ignition } \\
\text { wire }(\mathrm{cm})\end{array}$ & $\begin{array}{c}\text { Initial temperature } \\
\left({ }^{\circ} \mathrm{C}\right)\end{array}$ & $\begin{array}{c}\text { Maximum temperature } \\
\left({ }^{\circ} \mathrm{C}\right)\end{array}$ \\
\hline Sample1 & 0.00211 & 7 & 24.238 & 25.61 \\
Sample2 & 0.000406 & 7 & 27.831 & 29.091 \\
\hline
\end{tabular}

When they are completely burned, heats released by the two samples can be calculated with the following formula:

$\mathrm{Q}=\mathrm{cm} \Delta \mathrm{t}$

Where $\mathrm{c}$ is the specific heat capacity of water, $4200 \mathrm{~J} / \mathrm{kg} ; \mathrm{m}$ is water quality, $\mathrm{kg} ; \Delta \mathrm{t}$ is temperature change, ${ }^{\circ} \mathrm{C}$. Using the data in Table 1 , calculated heats for Sample 1 and Sample 2 are Q1 $=17171.952$ $\mathrm{J}$ and Q2 $=15770.16 \mathrm{~J}$, respectively. The calorific value of Sample 1 is $8.138365877 \mathrm{MJ} / \mathrm{kg}$; and the calorific value of Sample 2 is $38.84275862 \mathrm{MJ} / \mathrm{kg}$.

\section{Conclusions}

Using oil sludge samples from a sewage treatment plant on North China oilfield, pyrolysis experiments and calorific value determination experiments were conducted. According to these experimental data, the activation energy and frequency factors could be calculated. Thermo-gravimetric analyses and thermal analyses are carried out as well. The effects of heating rate, temperature and time on pyrolysis reactions were given. Experimental data mainly come from experimental instruments. Because instruments have some errors, experimental data got some deviation.

\section{Acknowledgements}

This work was financially supported by a 2015 grant (KM201510017009) from Science Research Development Program of Beijing Education Council, P.R. China.

\section{References}

[1] Jun Li, Yatian Luo, Sa Ding: Energy and Environmental Protection, 05( 2007), p. 12-14.

[2] Roberto Fernandes, Gaspar González, Elizabete Lucas: Colloid and Polymer Science, (2005), p. 28-34.

[3] Haoyuan Tang, Yuqi Jin, JianhuaYan: Power System Engineering, 04(2008), p 13-15. 
[4] Wanfu Wang, HaoJin, Feng Shi, Peng Liu, Huang Jie: Petroleum and Natural gas chemical industry, 02(2010), p.173-177.

[5] Chun Wu, Jianjun Zhou, Zhaocheng Zhao, Dongfeng Zhao, Yong Jiang: Environmental pollution and control, 10(2007), p. $759-762$. 